\title{
Semi-Inverse Design Optimization of Film Cooling Arrangement and Its Prediction of Coolant Amount of HPT Vanes
}

\author{
CHI Zhongran ${ }^{1}$, LIU Haiqing ${ }^{2}$, and ZANG Shusheng ${ }^{1}$ \\ ${ }^{1}$ School of Mechanical Engineering, Shanghai Jiao Tong University \\ No. 800 Dongchuan Rd., Minhang District, Shanghai 200240, China \\ chizr@sjtu.edu.cn \\ ${ }^{2}$ Shanghai Advanced Research Institute, Chinese Academy of Sciences
}

\begin{abstract}
Film cooling design is essential for modern HPT vanes. In this paper, a semi-inverse design optimization (SIDO) method for the film cooling arrangement of HPT vanes is introduced, which is based on a combinatorial optimization algorithm, a 1D heat conduction model and CFD methods. The SIDO method can optimize the total coolant amount of the film cooling structure while ensuring an acceptable metal temperature distribution. The optimization methodology was tested on a 2D vane derived from the 1st stage nozzle of a heavy-duty gas turbine, and the optimization result was validated by the conjugate heat transfer (CHT) CFD simulations. In further study, the SIDO method is applied to predict the optimal (necessary) coolant amount of the vane at various design conditions with different inlet temperature, maximal metal temperature allowed, heat conductivity of $\mathrm{TBC}$, and intensity of internal/film cooling structures. The quantitive results suggested that the inlet temperature and the maximal metal temperature allowed are arbitrary to the necessary coolant amount. Improving film cooling performance is more effective to save coolant compared with internal cooling, especially at higher inlet temperature level.
\end{abstract}

\section{NOMENCLATURE}

$D \quad$ Diameter of film hole

d Thickness

$h \quad$ Convective heat transfer coefficient

$k \quad$ Turbulence kinetic energy / Number of

sample points on PS \& SS

Objective function

Mass flow

Population size (of GA)

Number of candidate holes

Pressure

Total pressure

Wall heat flux

Temperature

Total temperature

Streamwise distance

Bit of the design variable

Spanwise (lateral) distance

Greeks

$\eta \quad$ Adiabatic film cooling effectiveness

Presented at International Gas Turbine Congress 2015 Tokyo

November 15-20, Tokyo, Japan

Manuscript Received on November 26, 2015

Review Completed on November 15, 2016
Heat conductivity

Turbulent dissipation rate

$\begin{array}{ll}\begin{array}{l}\text { Subscripts } \\ \text { ave }\end{array} & \text { Area-averaged } \\ \mathrm{c} & \text { Coolant / With cooling / Coolant side } \\ \mathrm{c} 1 & \text { Coolant Inlet \#1 } \\ \mathrm{c} 2 & \text { Coolant Inlet \#2 } \\ \mathrm{f} & \text { Film cooling } \\ \mathrm{g} & \text { Hot gas in cascade passage / Gas side } \\ \mathrm{i} & \text { Vane cascade inlet } \\ \mathrm{max} & \text { Maximum value } \\ \mathrm{mid} & \text { Centerline (downstream of a film hole) / } \\ & \text { mid-span section } \\ \mathrm{o} & \text { Rotor cascade outlet } \\ \mathrm{r} & \text { Relative value / Dimensionless value } \\ \mathrm{w} & \text { Wall (Metal beneath TBC layer) } \\ 0 & \text { Original value / Baseline }\end{array}$

Abbreviations

AAEV

AASF

CFD

CHT

GA

HPT

HTC

LE

PS

RANS

RNG

SIDO

SS

SST

TBC

TE

1D

2D

$3 \mathrm{D}$
Anisotropic Algebraic Eddy Viscosity

Anisotropic Algebraic Scalar Flux

Computational Fluid Dynamics

Conjugate Heat Transfer

Genetic Algorithm

High Pressure Turbine

Convective Heat Transfer Coefficient

Leading Edge

Pressure Side

Reynolds Averaged Navier-Stokes Equa-

tions

Renormalization Group

Semi-Inverse Design Optimization

Suction Side

Shear Stress Transport

Thermal Barrier Coating

Trailing Edge

One Dimensional

Two Dimensional

Three Dimensional

\section{INTRODUCTION}

Better gas turbine performance calls for higher turbine inlet temperature. Therefore, cooling structures are installed in the HPT components to protect them from the hot gas. The internal cooling method and external cooling method are the two major categories of the cooling structures commonly used. The external cooling method, or film cooling, uses discrete holes located on the blade surface to eject the cooling air and form a coolant film, which keeps 
the hot gas away from blade surface. The arrangement of film cooling holes shall be carefully decided accommodating the design conditions and requirements during the cooling design of HPT vanes and blades. Since film cooling has an arbitrary cooling effect under higher thermal load, advanced design methods for film cooling structures are obviously valuable for the development of modern/future gas turbines.

In traditional gas turbine cooling design, the cooling structures of HPT components are initiated, modified, and finally decided according to the results of 1D flow-network calculations with experimental correlations, 2D/3D heat conduction analysis, equivalent experiments, and engine tests. These evaluation approaches can be deemed as solving 'direct problems', that only the performance (coolant mass flow, heat transfer coefficient, film cooling effectiveness, and metal temperature distribution, etc.) of the input configuration is computed or measured as a consequence. When the designer seeks for a better cooling structure, a number of evaluations should be carried out, which is always elaborating and time-consuming. Even though, the direct design cannot guarantee that the final scheme is 'optimal', as the design iterations highly depends on the experiences and judgments of the designers.

The inverse design method was initiated to fix the shortcomings of the direct design. The inverse design method uses modified computational models that can be solved by iterating, and then a geometry providing the desired performance (pressure distribution or isentropic Mach number distribution on the surface, etc.) can be obtained directly and efficiently. It was firstly utilized in the aerodynamic design of 2D profile by Lighthill [1]. Korn [2], Léonard et al [3], and Vito et al [4] introduced the inverse design method for turbine cascades based on linearized isentropic equations, Euler equations, and $\mathrm{N}-\mathrm{S}$ equations. Also a detailed review of the inverse design methods for aerodynamic design has been presented by Dulikravich [5] in 1992. As for the application of inverse design methods in turbine cooling design, Dulikravich and Martin [6,7] developed a multi-disciplinary design optimization system for the aero- thermo-elastic design of internally-cooled turbine vanes and blades. However, as mentioned by Talya et al [8], using more than one design criterion in the inverse design is difficult to realize. Also, the modeling of complex cooling structures based on the inverse design method is more difficult compared with the direct method.

In recent years, the computer-automated design optimization method based on optimization algorithms and CFD simulations was introduced to the turbine cooling design. Through optimization methods, better cooling structures can also be found automatically, but without the difficulty of numerical modeling in the inverse design methods mentioned above. Some background of engineering optimization has been given by Dulikravich et al [10], indicating the possibility of optimization using genetic algorithms (GA). Martin [7,9] presents the problem of aero-thermo-elastic optimization of the convective cooled blade and gives the methodology, strategy and computer program dealing with it. Talya [8] studied the methods for blade profile and 2D film cooling optimization. Verstraete et al $[11,12]$ studied the optimization of a U-bend for minimal pressure loss. Lee et al $[13,14]$ optimized a fan-shaped film hole to find the effect of geometric variations on the cooling performance. For cooling structures with more complex geometries, the authors of this paper studied the optimization methodology of shaped film cooling holes [15] and cooling system of an internally-cooled vane [16] based on GA and 3D CFD methods. Though cooling structures with favorable performance were obtained automatically, each optimization search commonly costs hundreds of CFD runs and several weeks of time. As for the optimization of film cooling arrangement, Johnson et al [17] carried out a GA optimization of the locations of film cooling holes on the pressure side of a HPT vane using CFD methods. Improvements in adiabatic film cooling effectiveness were achieved at all spanwise locations through the optimization with a considerable computational cost of more than one thousand CFD runs.

It can be seen that most of the inverse design studies mentioned above were all limited to aerodynamic design or cooling design of quite simple structures. On the other hand, the computational costs of optimization using CFD models were too high for engineering use. To achieve better authenticity, accuracy, efficiency and automation of the film cooling design of HPT vanes, a design method which employs the concepts of both inverse design method and optimization method is developed and introduced in this paper. The basic thought of the method is to optimize the total coolant amount of the film cooling structure while ensuring an acceptable cooling performance. Therefore the optimal coolant amount could be found according to the thermal load of the vane and the cooling scheme adopted. Furthermore, the optimal coolant amount at different design conditions is studied utilizing the developed method.

\section{OPTIMIZATION METHODOLOGY}

A semi-inverse design optimization method (SIDO) is developed specifically for the cooling design of turbine vanes. The aim of the SIDO method is to automatically and efficiently find the optimum arrangement of film cooling holes according to the distribution of thermal loads on the vanes.

\section{Design Criteria and Constraints}

The SIDO method is different from the traditional film cooling design methods in terms of design criteria and constraints. As shown in Table. 1, in traditional film cooling design, a constraint on maximal coolant amount would be given by engine cycle design. The cooling designers shall use the limited coolant to effectively cool the blades accommodating the requirements of metal temperature and heat flux. As for the former optimization studies regarding film cooling structures, the total coolant amounts were always deemed as constrains, or even fixed during the design optimization. On the other hand, the optimization objectives were mostly the functions of film cooling effectiveness or metal temperature distributions. One major disadvantage of these design/optimization methods is that the coolant amount was estimated by empirical correlations. When an improper (insufficient, especially) coolant amount was given at the first step, the adjustment always results in additional difficulties in the engine design process.

In contradiction to the past methods and studies, the optimization objective of the presented the SIDO method is the total coolant amount while the constraint represents the cooling performance required. In another word, the SIDO method is to find the optimum film cooling structure which not only ensures an acceptable cooling performance but also minimizes the coolant amount. Subsequently a 'necessary' coolant amount can be found, which avoids using the empirical equations to estimate the coolant amount It is also hoped that the SIDO method could design a uniform wall temperature without hot spots or over-cooled zones.

Table. 1 Comparison of design criteria and constraints

\begin{tabular}{ccc}
\hline $\begin{array}{c}\text { Design } \\
\text { method }\end{array}$ & Total coolant amount & $\begin{array}{c}\text { Metal temperature / } \\
\text { Wall heat flux }\end{array}$ \\
\hline $\begin{array}{c}\text { Traditional } \\
\text { Most of former } \\
\text { optimizations }\end{array}$ & Constraint & Target \\
SIDO (present) & Optimization Objective & Constraint \\
\hline
\end{tabular}

\section{D Heat Transfer Model}

The SIDO method of film cooling arrangement is based on a 1D heat transfer model of HPT vanes. As mentioned above, in the 
SIDO method, the metal temperature and wall heat flux are deemed as constraints. However, it is very difficult to directly put these constraints into the mathematical models of an inverse design method. In substitution, a minimal film cooling effectiveness $\eta_{\text {min }}$ calculated by the 1D model is used as the constraint of the inverse design, which well represents the limitations of metal temperature and wall heat flux in quantity.

To build the 1D model, some assumptions and approximations shall be used as below:

a) Convective heat transfer on gas side is dominated by adiabatic wall temperature $T_{\mathrm{g}, \mathrm{c}}$ (with film cooling) and heat transfer coefficient (HTC) $h_{\mathrm{g}}$.

b) Convective heat transfer on coolant side is dominated by coolant temperature $T_{\mathrm{c}}$ and heat transfer coefficient $h_{\mathrm{c}}$.

c) Heat conduction in metal and TBC occurs only on the normal direction (from the gas side to coolant side). Lateral heat conduction is neglected.

d) Heat conductivities of metal and TBC $\left(\lambda_{\mathrm{w}}\right.$ and $\left.\lambda_{\mathrm{TBC}}\right)$ are both constant, regardless of temperature change.

e) Convective heat transfer inside film holes is neglected.

Subsequently, a 1D heat transfer model can be built at each point on the vane surface using the local heat transfer parameters, as shown in Fig. 1.

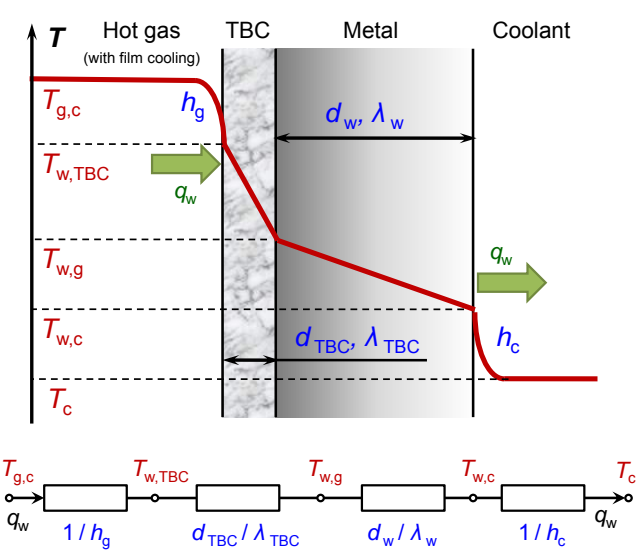

Fig. 1 1D heat transfer model of turbine vane

From the 1D model in Fig. 1, the following equations can be derived:

$$
\begin{gathered}
q_{\mathrm{w}}=\frac{T_{\mathrm{w}, \mathrm{g}}-T_{\mathrm{c}}}{\frac{d_{\mathrm{w}}}{\lambda_{\mathrm{w}}}+\frac{1}{h_{\mathrm{c}}}} \\
T_{\mathrm{g}, \mathrm{c}}=T_{\mathrm{w}, \mathrm{g}}+\frac{q_{\mathrm{w}} d_{\mathrm{TBC}}}{\lambda_{\mathrm{TBC}}}+\frac{q_{\mathrm{w}}}{h_{\mathrm{g}}}
\end{gathered}
$$

in which,

$T_{\mathrm{w}, \mathrm{g}}$-- Metal temperature on gas side.

$T_{\mathrm{c}}$-- Coolant temperature.

$h_{\mathrm{c}}-$ - Convective HTC on coolant side.

$T_{\mathrm{g}, \mathrm{c}}-$ - Adiabatic wall temperature with film cooling.

$h_{\mathrm{g}}$-- Convective HTC on gas side.

$d_{\mathrm{w}}$-- Thickness of metal.

$\lambda_{\mathrm{w}}-$ - Heat conductivity of metal.
$d_{\mathrm{TBC}}--$ Thickness of TBC.

$\lambda_{\text {ТВC }}-$ - Heat conductivity of TBC.

$q_{\mathrm{w}}--$ Wall heat flux.

Besides, two additional equations are added considering the film cooling effects:

$$
\begin{gathered}
\eta=\frac{T_{\mathrm{g}}-T_{\mathrm{g}, \mathrm{c}}}{T_{\mathrm{g}}-T_{\mathrm{c}, \mathrm{f}}} \\
T_{\mathrm{c}, \mathrm{f}}=T_{\mathrm{c}}+\frac{q_{\mathrm{w}}}{m_{\mathrm{c}} c_{p}}
\end{gathered}
$$

in which,

$\eta$-- Adiabatic film cooling effectiveness.

$T_{\mathrm{g}}$-- Adiabatic wall temperature without film cooling.

$T_{\mathrm{c}}$-- Coolant temperature.

$T_{\mathrm{c}, \mathrm{f}}-$ - Temperature of film jets.

$m_{\mathrm{c}}-$ - Coolant mass flow per surface unit.

Lower adiabatic film cooling effectiveness $\eta$ results in larger wall heat flux $q_{\mathrm{w}, \mathrm{c}}$ and higher metal temperature $T_{\mathrm{w}, \mathrm{g}}$. Hence, when a maximal metal temperature $T_{\mathrm{w}, \mathrm{g}, \max }$ is given as a limitation, a minimal film cooling effectiveness $\eta_{\min }$ at each point on the vane surface can be calculated based on Eq. (1) Eq. (4), as shown in Eq (5) and Eq. (6):

$$
\begin{gathered}
\eta_{\text {min }}=\frac{T_{\mathrm{g}}-\left(T_{\mathrm{w}, \mathrm{g}, \max }+\frac{q_{\mathrm{w}} d_{\mathrm{TBC}}}{\lambda_{\mathrm{TBC}}}+\frac{q_{\mathrm{w}}}{h_{\mathrm{g}}}\right)}{T_{\mathrm{g}}-\left(T_{\mathrm{c}}+\frac{q_{\mathrm{w}}}{m_{\mathrm{c}} c_{p}}\right)} \\
q_{\mathrm{w}}=\frac{T_{\mathrm{w}, \mathrm{g}, \max }-T_{\mathrm{c}}}{\frac{d_{\mathrm{w}}}{\lambda_{\mathrm{w}}}+\frac{1}{h_{\mathrm{c}}}}
\end{gathered}
$$

Furthermore, if both the maximal metal temperature $T_{\mathrm{w}, \mathrm{g}, \max }$ and the maximal wall heat flux $q_{\mathrm{w}, \max }$ are given as limitations, the wall heat flux $q_{\mathrm{w}}$ in Eq. (5) shall use the minor value between $q_{\mathrm{w}}$ calculated by Eq. (6) and $q_{\mathrm{w}, \max }$.

Using Eq. (5) and Eq. (6), the distribution of $\eta_{\min }$ on the vane surface can be computed according to the vane geometry, material properties, and boundary conditions. It is anticipated that achieving an adiabatic film cooling effectiveness $\eta$ higher than $\eta_{\min }$ should ensure the desired values of metal temperature and wall heat flux. Therefore an $\eta$ distribution higher than $\eta_{\min }$ is used as the target of the inverse design. As the inverse design method introduced here does not directly employ the constraints of metal temperature and wall heat flux, but uses a derived constraint $\eta_{\min }$, the method is named as a 'semi' one.

\section{Parameterization}

Since the difficulty and computational costs of optimization process could increase significantly as the number of design variables multiples, it is important to wisely select the design variables according to the requirements of cooling design. Only the design parameters which have primary influences on the cooling performance while quite difficult to be decided in advance shall be put into the optimization as variables.

Former studies have well illustrated the mechanism of film 
cooling [20]. It is recognized that the optimum configurations of film holes mainly depend on their locations on the vane surface. For instance, an array of showerhead film holes is always arranged at LE, while cylindrical holes with compound angles or shaped holes with optimum expansion angles are used on PS and SS. In this situation, the arrangement of the shaped holes on PS and SS becomes predominant. Therefore, in the SIDO method the configurations of shaped holes can be directly given according to former studies, which are not changed in the optimization process. Also the showerhead film cooling is conservatively designed in advance. For all that, the object of the SIDO method only includes the arrangement of shaped holes on PS and SS.
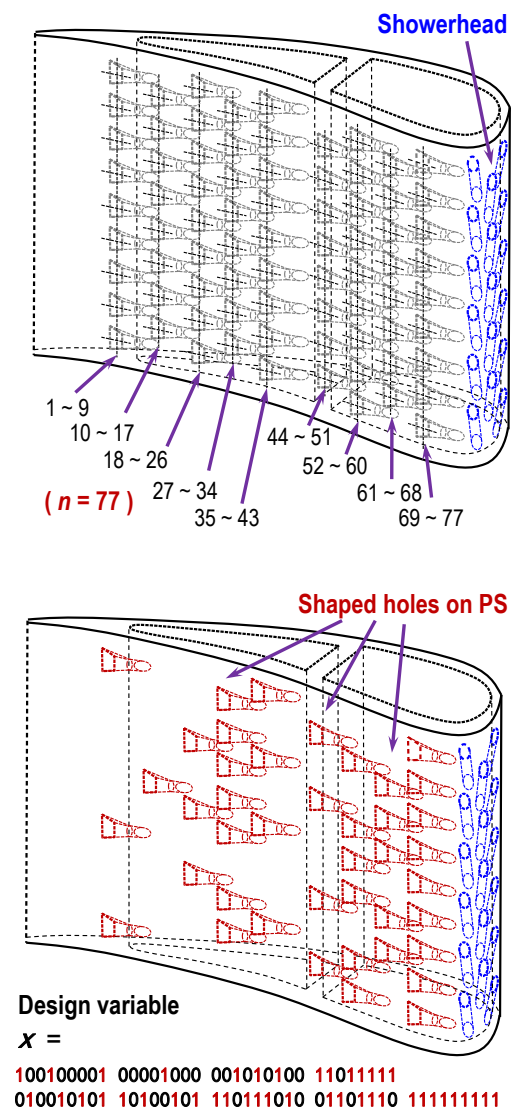

Fig. 2 Parameterization of film cooling arrangement (example): a) Step 1 -- plot the array of candidate locations; b) Step 2 -place the holes according to the design variable.

The arrangements of shaped holes on PS and SS are designed with a two-step approach, as presented in Fig. 2. In the first step, an equally spaced array is plotted on the vane surface, in which each node represents a candidate location of shaped holes. The array is plotted in advance and fixed during the optimization process. The spanwise distance of the array equals to the optimal pitch distance of the given hole geometry. The streamwise distance of the array is minimized while ensuring the limitation of strength and the requirement of manufacturing. Also, the array does not map the zones where film holes shall not be placed on (SS downstream the throat, surface adjacent to clip boards, etc.). Typically, the array of candidate locations on PS and SS is with a total node number $n \approx 100 \sim$ 600 regarding the size of the vane. In the second step, a binary code $\boldsymbol{x}=\left[x_{j}\right]$ with $n$ bits is given as the design variable, which defines the hole locations selected from the array (selected, $x_{j}=1$; abandoned, $x_{j}=0$ ). Subsequently, shaped holes with the given geometry are placed at the selected locations and form the film cooling structures on PS and SS. Therefore the parametric design of the film cooling structure is reduced to setting an $n$-bit binary code $x$, which is concise enough to be adopted in the optimization.

\section{Mathematical Model of SIDO Method}

According to the widely-used formula for the superposition of film cooling (see Eq. (7)), the constraint of film cooling design is given by an inequality at each point on the vane surface, as shown in Eq. (8), that the selected film holes shall form a film coverage with adiabatic film cooling effectiveness higher than $\eta_{\min }$ calculated by Eq. (5).

$$
\begin{gathered}
\eta=1-\left(1-\eta_{1}\right)\left(1-\eta_{2}\right) \ldots\left(1-\eta_{j}\right) \\
\eta_{\min } \leq 1-\left(1-x_{1} \eta_{1}\right)\left(1-x_{2} \eta_{2}\right) \ldots\left(1-x_{j} \eta_{j}\right) \ldots\left(1-x_{n} \eta_{n}\right)
\end{gathered}
$$

in which,

$x_{j}$-- The $j$ bit of the binary design parameter $\boldsymbol{x}$.

$\eta_{j}$-- Local adiabatic film cooling effectiveness when only hole $j$ is working.

As mentioned above, the optimization objective of the SIDO method is the total coolant amount of film holes $M$, which is the sum of coolant mass flows of all the selected film holes. The coolant mass flow of each candidate hole $m_{j}$ is decided by its inlet and outlet pressure as well as the flow resistance. The inlet pressure of a film hole equals to the pressure level of the cavity, which is fixed to ensure the backflow margin of all the connected film holes. (After film cooling is decided by the SIDO method, the internal cooling shall be designed in detail accommodating the required inlet pressure of film holes.) As the locations and shapes of the candidate holes are decided in advance, their flow resistances and outlet pressures are also fixed. For all that, the coolant amount of each candidate hole $m_{j}$ can be evaluated in advance and considered independently during the optimization.

The mathematical model of the SIDO method can be constructed based on the parameterization method mentioned above together with the 1D model, as shown in Eq. (9) Eq. (11). It is notable to see that the constraint function Eq. (10) is constructed based on Eq. (8) at multiple points, which are equally spaced on the vane surface with a total number $k$ around $10^{4}$. It is anticipated that the scattered constraint function can limit the $\eta$ distribution as a whole.

$$
\min M(\boldsymbol{x})=\sum_{j=1}^{n} m_{j} x_{j}
$$

$$
\begin{gathered}
\text { s. t. } \sum_{j=1}^{n} x_{j} \ln \left(1-\eta_{i j}\right) \leq \ln \left(1-\eta_{\min , i}\right), i=1,2, \ldots, k \\
x_{j} \in\{0,1\}, j=1,2, \ldots, n
\end{gathered}
$$

in which,

$i$-- Scattered points on PS and SS, $i=1 \sim k, k \approx 10^{5}$.

$j$-- Candidate film holes, $j=1 \sim n$.

$m_{j}$-- Coolant mass flow of candidate film hole $j$.

$\eta_{i j}$-- Adiabatic film cooling effectiveness at point $i$ when only hole $j$ is working. 
$\eta_{\min , i}-$ - The constraint of film cooling effectiveness at point $i$ calculated by Eq. (5).

Through solving the optimization problem given by Eq. (9) Eq. (11), an optimal design variable $\boldsymbol{x}_{\mathrm{opt}}$ representing the optimum arrangement of film cooling holes can be found, which not only minimizes the coolant amount but also ensures a sufficient film coverage.

\section{Genetic Algorithm for Combinatorial Optimization}

When the optimization model defined by Eq. (9) Eq. (11) is built, a GA optimization search can be carried out to find the optimal film cooling arrangement. GA is widely used in engineering optimization. In a GA optimization search, a population of numerical strings was used to encode a group of candidate solutions for each step. The numerical strings (individuals) in the population evolved toward better solutions during the optimization process which simulates the mechanism of natural selection and evolution. Details about the GA and its applications can be found in [21].

In this study, an improved GA is used to solve the combinatorial optimization problem. Several modifications are proposed to the basic GA procedure, including a fitness-based crossover operator (the fusion operator by Beasley \& Chu [22]) and a new heuristic feasibility operator which significantly accelerates the optimization search. Without the heuristic feasibility operator, most of the individuals generate during GA search would be invalid, and GA search could not converge consequently. The detailed steps of the proposed GA are given as below:

(a) Build an initial population of $N$ randomly generated solutions $(N \approx 1.5 n)$.

(b) Randomly select two individuals $\boldsymbol{x}_{\mathrm{P}, 1}$ and $\boldsymbol{x}_{\mathrm{P}, 2}$ from the population.

(c) Combine $\boldsymbol{x}_{\mathrm{P}, 1}$ and $\boldsymbol{x}_{\mathrm{P}, 2}$ to form a new solution $\boldsymbol{x}_{\mathrm{C}}$ using the fusion crossover operator [22].

(d) Mutate ( 0 to 1 , or 1 to 0$) c$ randomly selected columns in $x_{\mathrm{C}}$ $(c \approx 0.05 n)$.

(e) By applying the heuristic feasibility operator, add some columns which can make $\boldsymbol{x}_{\mathrm{C}}$ feasible while cost minimal penalty to $M$, then remove redundant columns in $C$ which can mostly reduce $M$.

(f) If $x_{\mathrm{C}}$ is identical to any one of the solutions in the population, go to step (b); otherwise set counter +1 .

(g) Replace a randomly chosen solution with an above-average fitness in the population by $\boldsymbol{x}_{\mathrm{C}}$.

(h) Repeat steps (b) (g) until the counter reaches the limitation $(\approx 10000)$. The output $\boldsymbol{x}_{\mathrm{opt}}$ is the individual with the smallest $M$ in the population.

The optimization result $\boldsymbol{x}_{\mathrm{opt}}$ corresponds to the optimal film cooling arrangement.

\section{Optimization Flowchart}

The procedure of the SIDO method is presented in Fig. 3. The inputs of the SIDO method include the aerodynamic profile of the vane, the boundary conditions at the design point, and properties of metal and TBC.

In the first step, a preliminary design of the internal cooling structures is carried out, and the HTC of internal cooling structures is computed using empirical correlations. The showerhead film holes shall be designed in advance, and the configurations of the shaped holes on PS and SS shall be selected in this step. Then the array of candidate hole locations (as shown in Fig. 2 a)) is plotted on the vane surface. Subsequently, the film cooling performance and coolant mass flow of each candidate hole and the showerhead holes shall be respectively evaluated by CFD simulations, or by experiments for better accuracy. As a result, the matrix of $\eta_{i j}$ and the vector of $m_{j}$ are built, as shown in Fig. 4 a)

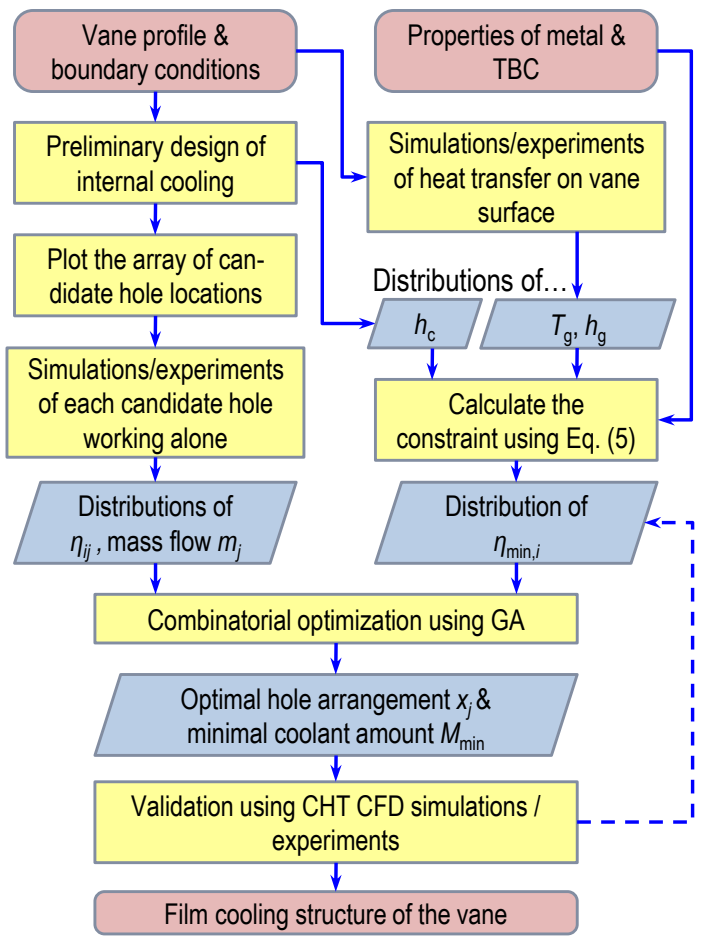

Fig. 3 Flow-chart of the SIDO method
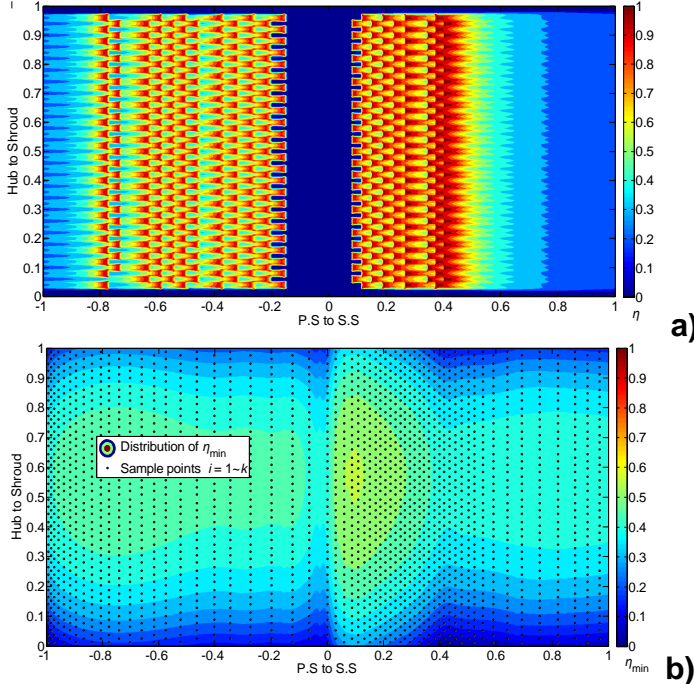

a)

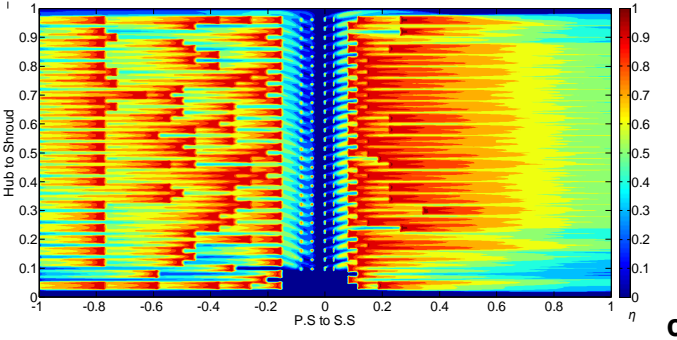

c)

Fig. 4 Distributions of adiabatic film cooling effectiveness: a) Candidate holes -- $\max \left(\eta_{j}\right)$; b) Constraint -- $\eta_{\min }$; c) Result -- $\eta_{\text {opt }}$.

On the other hand, a group of CFD simulations (or experi- 
ments for better accuracy) are carried out to get the distributions of $T_{\mathrm{g}}$ and $h_{\mathrm{g}}$. Together with the properties of materials and the distribution of $h_{\mathrm{c}}$, the vector of constraint $\eta_{\min , j}$ can be calculated using Eq. (5), as shown in Fig. 4 b). Therefore the optimization model defined in Eq. (9) Eq. (11) is constructed. An improved GA is used to solve the combinatorial optimization problem, and the optimal hole arrangement as well as the minimal coolant amount can be found as a result, as shown in Fig. 4 c). Finally, the designed cooling structures shall be validated using CHT CFD simulations or experiments if needed.

Regarding the combinatorial optimization using GA, the input data representing the film cooling properties $\left(\eta_{i j}\right.$ and $\left.m_{j}\right)$ and constraint $\left(\eta_{\min , j}\right)$ are independently acquired. Therefore, if the external heat transfer conditions are altered, only the simulations/experiments for the distributions of $T_{\mathrm{g}}, h_{\mathrm{g}}$, and $q_{\mathrm{rad}}$ are to be repeated. Moreover, if the properties of metal or TBC is changed, only the constraint $\eta_{\min , j}$ shall be recalculated using Eq. (5), which means no simulation/ experiment is required to reconstruct the model.

\section{VERIFICATION OF THE OPTIMIZATION METHOD}

\section{Original Vane and Design Condition}

In order to verify the capability of the SIDO method, a design optimization of film cooling arrangement on the vanes of a linear cascade is carried out in this study. The cascade is derived from the 1st stage nozzle of a heavy-duty gas turbine engine.

The original cooling structure of the vane is shown in Fig. 5. The vane is separated into three cooling cavities with impingement tubes. Showerhead film holes with spanwise inclination are arranged at LE, and shaped holes with streamwise inclination are placed on both PS and SS. Three clipboards with impingement holes are arranged near TE.

In this study, the internal cooling structures as well as the showerhead film holes are maintained during the optimization. The shaped film holes on PS and SS are redesigned using the SIDO method.

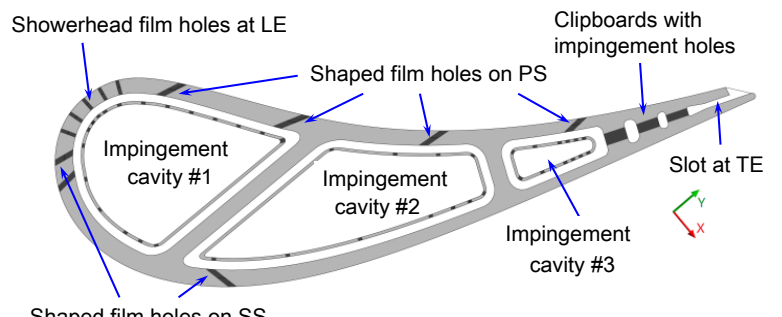

Fig. 5 Original vane

The design optimization of these film cooling holes are carried out under the design condition listed in Table. 2. The total temperature at the inlet is not uniform on the spanwise direction. The peak of inlet total temperature appears at $58 \%$ span. The convective heat transfer coefficient on all the surfaces with impingement cooling is assumed to be uniform, which is estimated by an empirical correlation.

Table. 2 Design condition

\begin{tabular}{ccccc}
\hline$p_{\mathrm{g}}^{*} / \mathrm{MPa}$ & $T_{\mathrm{g}, \text { ave }}^{*} / \mathrm{K}$ & $T_{\mathrm{g}, \max }^{*} / \mathrm{K}$ & $T_{\mathrm{c}}^{*} / \mathrm{K}$ & $h_{\mathrm{c}} /\left(\mathrm{W} \mathrm{m}^{-2} \mathrm{~K}^{-1}\right)$ \\
\hline 2.8 & 1900 & 1990 & 820 & 2500 \\
\hline
\end{tabular}

\section{Candidate Film Holes}

As presented in the previous section, the parameterization of film holes uses a binary method by setting the candidate film holes on the vane. In this verification study, 493 candidate film holes are placed on the vane in twenty-one rows, as shown in Fig. 6 and Table. 3. Here a shaped hole configuration is used, which is the same as that of the original vane.

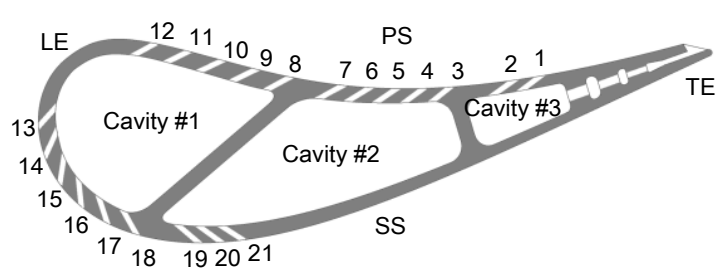

Fig. 621 rows of candidate film holes

Table. 3 Geometrical parameters of candidate film holes

\begin{tabular}{ccccc}
\hline $\begin{array}{c}\text { Row } \\
\text { No. }\end{array}$ & Side & $\begin{array}{c}\text { Dimensionless } \\
\text { Streamwise location }\end{array}$ & $\begin{array}{c}\text { Number of } \\
\text { candidate } \\
\text { holes }\end{array}$ & $\begin{array}{c}\text { Jet } \\
\text { angle } \\
\left({ }^{\circ}\right)\end{array}$ \\
\hline 1 & PS & 0.734 & 24 & 27.5 \\
2 & PS & 0.694 & 23 & 27.5 \\
3 & PS & 0.597 & 23 & 35.0 \\
4 & PS & 0.556 & 24 & 35.0 \\
5 & PS & 0.516 & 23 & 35.0 \\
6 & PS & 0.476 & 24 & 35.0 \\
7 & PS & 0.435 & 23 & 35.0 \\
8 & PS & 0.355 & 24 & 40.0 \\
9 & PS & 0.302 & 23 & 40.0 \\
10 & PS & 0.250 & 24 & 40.0 \\
11 & PS & 0.198 & 23 & 40.0 \\
12 & PS & 0.145 & 24 & 40.0 \\
13 & SS & 0.088 & 23 & 45.0 \\
14 & SS & 0.125 & 24 & 45.0 \\
15 & SS & 0.161 & 23 & 45.0 \\
16 & SS & 0.198 & 24 & 45.0 \\
17 & SS & 0.235 & 23 & 45.0 \\
18 & SS & 0.272 & 24 & 45.0 \\
19 & SS & 0.346 & 23 & 40.0 \\
20 & SS & 0.373 & 24 & 40.0 \\
21 & SS & 0.399 & 23 & 40.0 \\
\hline
\end{tabular}

\section{CFD Approach}

In the present study, RANS CFD method is adopted using a commercial CFX solver ANSYS CFX 12.1.

As mentioned above, a group of CFD runs shall be carried out in the SIDO process to get the adiabatic film cooling effectiveness of each candidate film hole. Considering the object cascade is linear and the candidate film holes are in a large number, it is assumed that the film cooling performance of all the film holes in one row are the same despite the spanwise location. Therefore the CFD domains can be simplified to a 2D slice with $1 / 25$ span of the vane when computing the matrix of $\eta_{i j}$, which corresponds to the pitch distance of the film holes. Coolant inlets with fixed total pressure are set on both hub and shroud surfaces of the cooling cavity connected to the film hole. Periodical boundary conditions are set between the hub and the shroud. Since the HTC of internal cooling is assumed to be constant, the impingement cooling structures are omitted. Pressure boundary conditions are separately set for the three cavities according the total pressure of cooling air and the pressure drop of the three impingement tubes. In these CFD runs, 
the inlet total temperature was set as $T_{\text {g.ave }}^{*}$ This is based on the approximation that the variation of mainstream temperature (resulting in a density ratio from 2.1 to 2.4 ) has very limited effect on the distribution of adiabatic film cooling effectiveness.

The CFD grids were generated using an in-house code developed specifically for mesh generation of cooled turbine blades and vanes [18]. As for the CFD simulation of candidate holes, the mesh size is 0.8 million according to the mesh dependence check. One example of the mesh is presented in . Most of the mesh elements are hexahedral with an average quality of 0.85 . Mesh facets on both sides of the periodical boundaries are one-to-one located. Boundary layer mesh is added at all the walls accommodating the $\mathrm{y}$-plus value required by the turbulence model used.

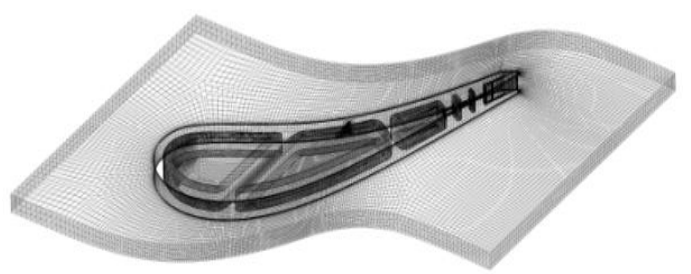

a)

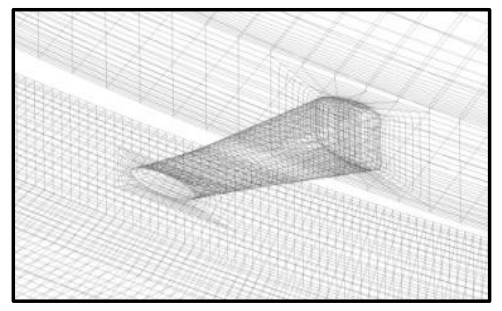

Fig. 7 Example mesh of the CFD run for a candidate hole: a) Overall view; b) Partial view near the hole.

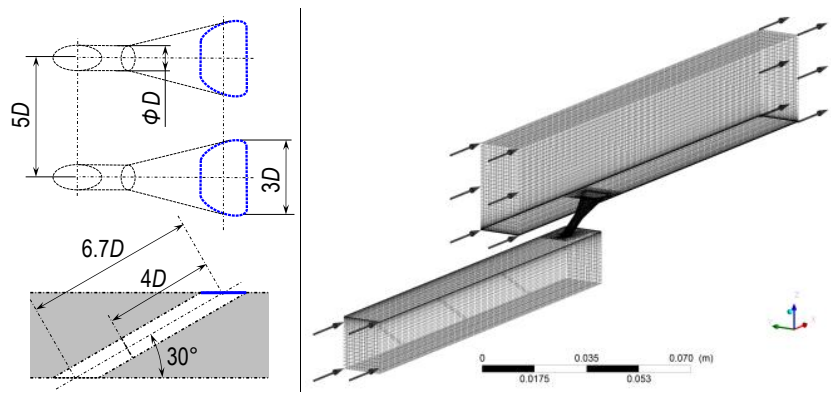

Fig. 8 Film hole geometry and computational domain of CFD validation $(D=3 \mathrm{~mm})$.

Experimental data of shaped film holes on a flat plate [23] were used to validate the numerical model before the optimization study. Pressure sensitive paint (PSP) was the measurement to obtain film cooling effectiveness. The Reynolds number of mainstream flow based on the cooling hole diameter was 6000 corresponding to the optimization. The geometry of selected film hole and the CFD domain are presented in Fig. 8.

Film cooling is characterized by a row of coolant jets injected into the hot crossflow. As this flow phenomenon is highly complex, unsteady and more detailed numerical methods like LES and DNS can give a better prediction of film cooling to some degree. However, the computational costs of these unsteady methods are too expensive to be applied in engineering design optimization. The accuracy of film cooling prediction using RANS method can be improved through developing anisotropic turbulence models. In RANS method, the Reynolds stress term and the turbulent scalar flux term are needed to be closed. Based on Boussinesq hypothesis, the eddy viscosity and scalar diffusion coefficient are applied to close the terms. In order to precisely solve the flow and heat transfer of film cooling, the turbulence model has to predict the eddy viscosity and scalar diffusion coefficient correctly.

In the present study, anisotropic modeling of turbulence, including Anisotropic Algebraic Eddy Viscosity (AAEV) model and Anisotropic Algebraic Scalar Flux (AASF) model [23], was used together with a CFD solver ANSYS CFX 12.1 to better predict film cooling performance during the optimization of the shaped holes. The AAEV-AASF model was added into the solver through a user-defined-function. The numerical methods are validated against experimental data of a shaped hole [23], as shown in Fig. 9. The four models can well predicted the lateral-averaged film cooling effectiveness, as shown in Fig. 9 a). However, as shown in Fig. 9 b), the RNG $k-\varepsilon$ model and SST model obviously over-predicted the film cooling effectiveness on the downstream centerline with errors up to $50 \% \sim 100 \%$. However, the AAEV-AASF model improved the accuracy of RNG $k-\varepsilon$ model and SST model and gave numerical results much closer to the experimental data. Similar effects can be observed by comparing the lateral distributions of film cooling effectiveness at different streamwise locations, as shown in Fig. 9 c). According to the experimental validation, the AAEV-AASF RNG $k-\varepsilon$ model is selected for the optimization study.
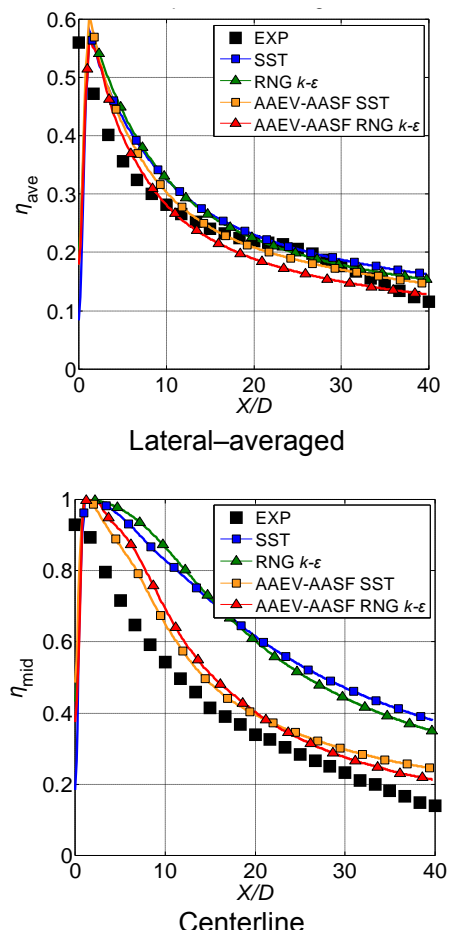

b)
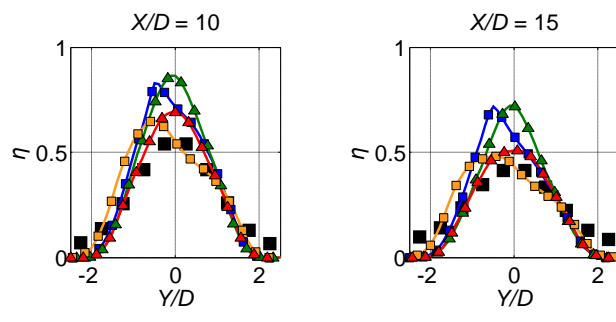

Different streamwise locations

Fig. 9 Validation of CFD methods 


\section{Optimization Result}

After the film cooling design optimization using the SIDO method, the optimized vane is compared with the original by conjugate heat transfer (CHT) CFD runs. Here a dimensionless wall temperature $T_{\mathrm{r}}$ is used the evaluate the cooling performance, as shown in Eq. (12). Obviouly, having local temperature $T_{\mathrm{r}}$ larger than one indicates that the local surface is not well cooled.

$$
T_{\mathrm{r}}=\frac{T_{\mathrm{w}}}{T_{\mathrm{w}, \max }}
$$

The wall temperature distributions of the two vanes predicted by CHT CFD runs are compared in Fig. $10\left(T_{\mathrm{w}, \max }=1180 \mathrm{~K}\right)$. As shown in Fig. 10 a), the seven rows of shaped holes can well protect the original vane. However, the film cooling arrangement designed by the SIDO method is scattered and not uniform, that more film holes are placed at the upstream part of the vane, as shown in Fig. $10 \mathrm{~b}$ ). After optimization, the average wall temperature (dimensionless) is slightly dropped by 0.003 (about $3 \mathrm{~K}$ in absolute value), while the total coolant amount is reduced from $3.26 \%$ to $3.07 \%$.

According to the verification, it is demonstrated that SIDO method can design the film cooling arrangement on PS and SS effectively. The film cooling performance design by the automated SIDO method can be equivalent or even better than the manually designed. Moreover, the necessary coolant amount is no longer to be estimated by empirical correlations, but can be directly computed and optimized during the optimization. Therefore, the optimal coolant amount at different design conditions could be studied utilizing the developed method, which is discussed in the following section of the paper.

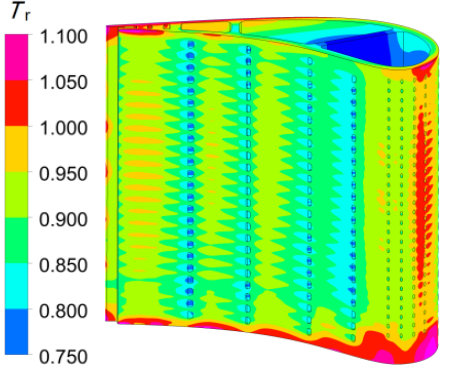

PS

Original $\left(m_{\mathrm{r}}=3.26 \%, T_{\mathrm{r}, \text { ave }}=0.889\right)$

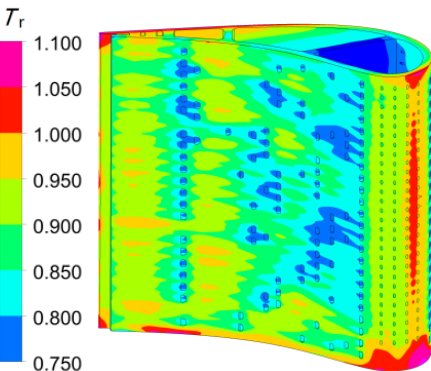

PS

Optimized $\left(m_{\mathrm{r}}=3.07 \%, T_{\text {rave }}=0.886\right)$
Fig. 10 Comparison of metal temperature distributions of vanes with original / optimized film cooling (CHT CFD)

Furthermore, the metal temperature distributions of optimized vane predicted by the 1D model and CHT CFD are shown in Fig. 11. It can be seen that the assumptions of the 1D model may lead so an overestimated wall temperature, mostly because of neglecting in-hole convective heat transfer and lateral heat conduction. However, the 1D model tend to underestimate the local wall temperature at downstream zones of SS, which mainly due to the error of superposition model of film cooling effectiveness.

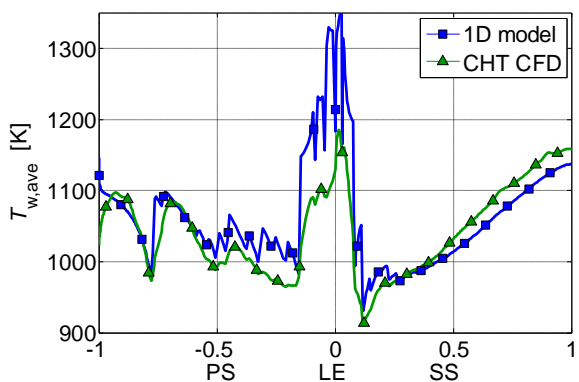

a)

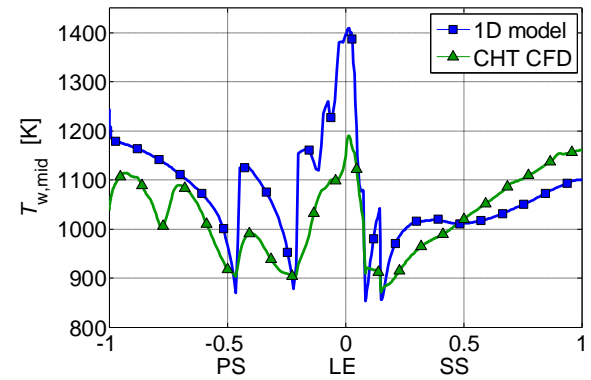

b)

Fig. 11 Metal temperature predicted by 1D model and CHT CFD: a) Spanwisely averaged; b) Mid-span section.

\section{OPTIMAL COOLANT AMOUNT AT VARIOUS DESIGN CONDITIONS}

As presented above, the SIDO method can automatically find the optimal arrangement of film cooling holes as well as the minimize coolant amount according to the design conditions. It is also notable to see that the computational cost of the SIDO method is determined by the CFD runs for $\eta_{i j}$ and $m_{j}$, which could be assumed to be independent from the variation of most design conditions (turbine inlet temperature, metal/TBC properties, internal cooling intensity, etc). Therefore, when one of these design conditions is altered, the SIDO method can efficiently carry out a new design through re-calculating the constraint $\eta_{\mathrm{min}, j}$ through carrying out a new simulation for external flow condition (distributions of $T_{\mathrm{g}}$ and $h_{\mathrm{g}}$ ) and then running a new GA search. Furthermore, if the external flow condition is also maintained, the SIDO process would cost only several minutes on a computer without CFD runs.

In this section, the effects of several design conditions on the optimal coolant amount of the vane is studied in quantity with the help of the SIDO method. Considering the SIDO method has well verified as introduced in the previous section, the results of the SIDO runs here are not verified using CHT CFD runs to reduce the computational cost. The analysis and discussion are focused on the relative value of the optimal coolant amount $m_{\mathrm{r}}$ (from film holes on PS and SS) at various design conditions, as defined by Eq. (13).

$$
m_{\mathrm{r}}=\frac{m_{\mathrm{c}, \mathrm{opt}}}{m_{\mathrm{g}, \mathrm{i}}}=\frac{M\left(\boldsymbol{x}_{\mathrm{opt}}\right)}{m_{\mathrm{g}, \mathrm{i}}}
$$


The object vane and the optimization model are the same as those introduced in the previous section. The only difference is that a variable HTC of internal cooling is used to build the optimization model depending on the coolant amount of the vane, as shown in Fig. 12. This treatment is to represent the variation of internal cooling caused by the change of coolant amount. So the GA search is solved in several iteration, until the optimal coolant amount and the internal HTC are converged.

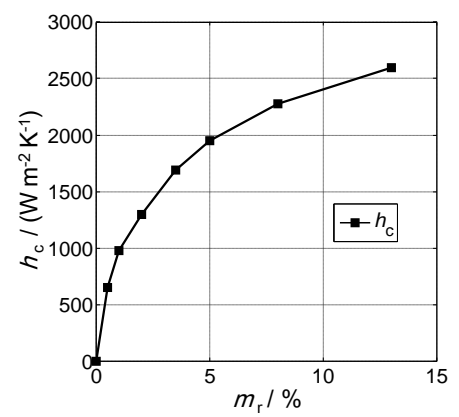

Fig. 12 Relationship between the coolant amount and HTC of internal cooling in the SIDO processes at various design conditions

\section{Effect of Turbine Inlet Temperature}

The effect of turbine inlet temperature on the optimal coolant amount of the vane is presented in Fig. 13. In this group of SIDO runs, the inlet temperature is ranged from $1425^{\circ} \mathrm{C}$ to $1675^{\circ} \mathrm{C}$. Correspondingly, the coolant temperature is ranged from $465^{\circ} \mathrm{C}$ to $565^{\circ} \mathrm{C}$, and the inlet total pressure is ranged from $2.4 \mathrm{MPa}$ to 3.4 MPa. $T_{\text {w max }}$ is set as $900{ }^{\circ} \mathrm{C}$, and the thickness / thermal conductivity of TBC are set as $150 \mu \mathrm{m} / 1.0\left(\mathrm{~W} \mathrm{~m}^{-1} \mathrm{~K}^{-1}\right)$.

As shown in Fig. 13, the increase of optimal coolant amount of

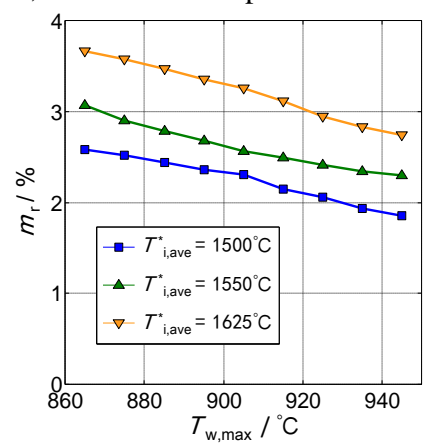

Maximal metal temperature allowed film holes on PS and SS via turbine inlet temperature is almost linear. The optimal coolant amount increases $0.7 \sim 0.8$ percentage when turbine inlet temperature is $100{ }^{\circ} \mathrm{C}$ higher.

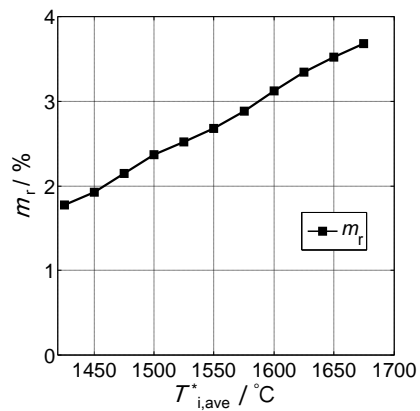

Fig. 13 Effect of inlet temperature on optimal coolant amount

\section{Effects of Material Properties}

The properties of metal and TBC can also affect the coolant amount required. Using alloy that can tolerate higher temperature and using TBC with lower heat conductivity can both reduce the optimal coolant amount. The effects of these material properties on the optimal coolant amount of the vane is presented in Fig. 14. The thickness of TBC is set as $150 \mu \mathrm{m}$.

From Fig. 14 a) it can be seen that the optimal coolant amount of film holes on PS and SS can be reduced by about 0.1 percentage when the maximal metal temperature is increased by $10^{\circ} \mathrm{C}$. When the heat conductivity of TBC is reduced from $2.0\left(\mathrm{~W} \mathrm{~m}^{-1} \mathrm{~K}^{-1}\right)$ to 1.0 $\left(\mathrm{W} \mathrm{m}{ }^{-1} \mathrm{~K}^{-1}\right.$ ), the total coolant amount can be saved by $0.2 \sim 0.3$ percentage. If the heat conductivity of TBC is further reduced to 0.7 $\left(\mathrm{W} \mathrm{m}^{-1} \mathrm{~K}^{-1}\right)$, the profit of coolant saving is more significant.

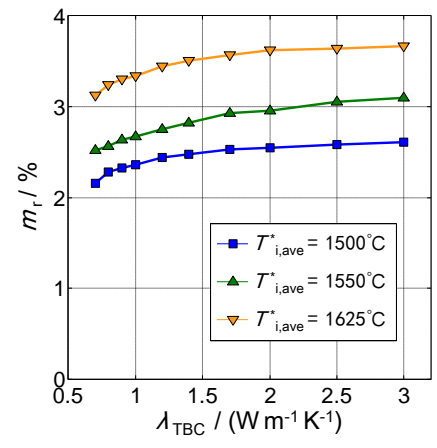

Heat conductivity of TBC layer b)

Fig. 14 Effects of material properties on optimal coolant amount

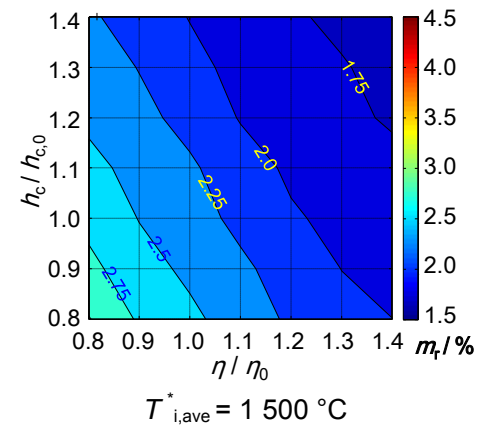

a)

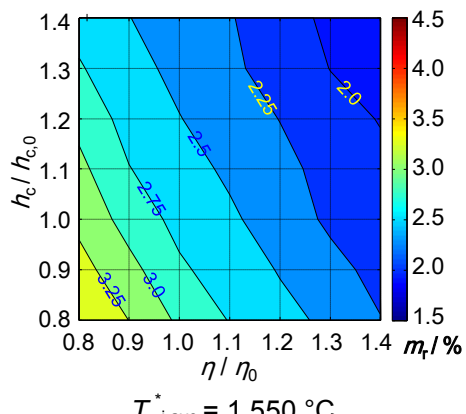

$T^{*}{ }^{*}$, ave $=1550^{\circ} \mathrm{C}$

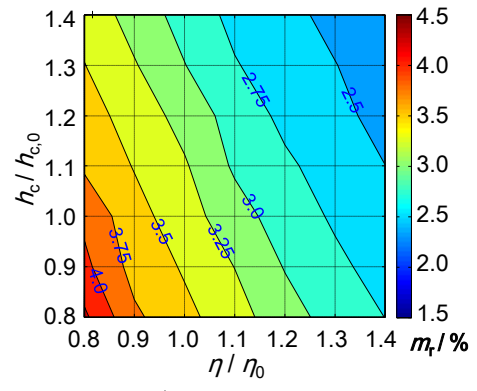

b)

$T^{\star}{ }_{\mathrm{i} \text { ave }}=1625^{\circ} \mathrm{C}$

Fig. 15 Effects of internal cooling HTC and adiabatic film effectiveness on optimal coolant amount 

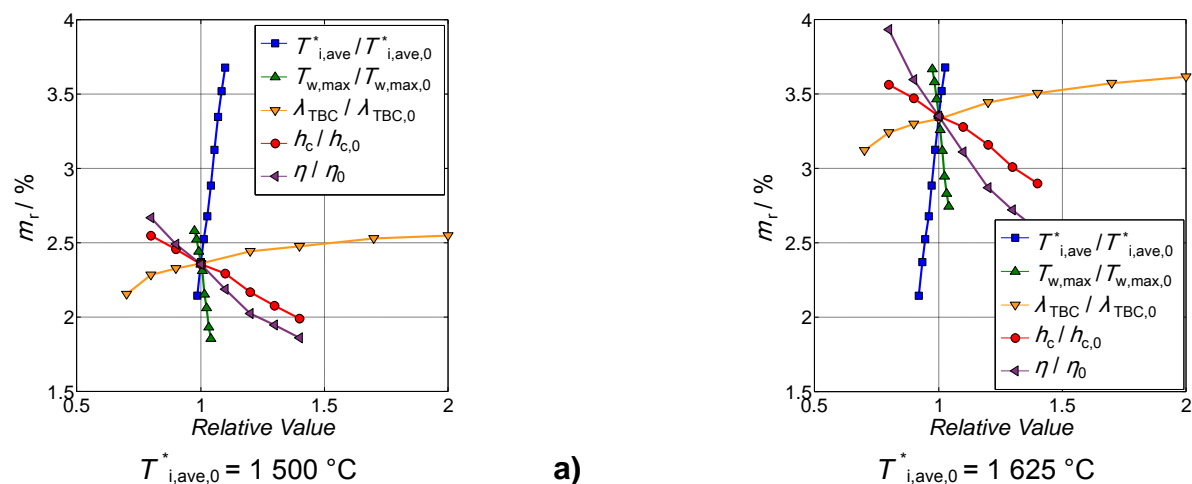

b)

Fig. 16 Comparison of multiple effects

\section{Effects of Internal / External Cooling Intensity}

With the help of more advanced cooling technique, increasing internal cooling HTC and adiabatic film effectiveness can both contribute to save coolant amount. This piece of study is performed with the assumptions that the internal / external cooling performance is comparatively dropped or increased. The values of internal cooling HTC and adiabatic film effectiveness are ranged from $80 \%$ to $140 \%$ of the baseline values. The baseline values of internal cooling HTC are defined by Fig. 12, and those of adiabatic film cooling effectiveness are computed by CFD runs. The SIDO runs are carried out at three different inlet temperatures, and the corresponding optimal coolant amounts are presented by 2D contours, as shown in Fig. 15.

As shown in Fig. 15, the higher internal cooling HTC and / or adiabatic film effectiveness are, the lower optimal coolant amount is. And the marginal profit of intensifying internal / external cooling is gradually dropping as the relative value increases.

It is notable to see that the contour lines in Fig. 15 c) with higher thermal load is obviously steeper than those Fig. 15 a) with low thermal load. As shown in Fig. 15 c), in the saving coolant point of view, the contribution of improving film cooling by $10 \%$ is about 0.3 percentage, which is almost the same as that of improving internal cooling by $20 \%$. Even if the HTC profile in Fig. 12 gets higher or lower in general, similar phenomena could still be observed, that the effect of film cooling effectiveness on necessary coolant amount intensifies quicker as $T^{*}{ }_{\text {i,ave }}$ increases compared with internal cooling. So it is suggested that developing film cooling technology (using shaped holes with better exit shaping, for instance) should be more effective than developing internal cooling when the turbine inlet temperature gets higher.

\section{Comparison of Multiple Factors}

In Fig. 16, the effects of all the factors mentioned above on the optimal coolant amount are simultaneously compared in one figure using relative values, in which $T_{\mathrm{w}, \max , 0}$ is $900{ }^{\circ} \mathrm{C}, \lambda_{\mathrm{TBC}, 0}$ is 1.0 (W $\mathrm{m}^{-1} \mathrm{~K}^{-1}$ ), and $h_{\mathrm{c}, 0} / \eta_{0}$ are the baseline values of internal / external cooling.

From Fig. 16 it can be seen that turbine inlet temperature and maximal metal temperature allowed $T_{\mathrm{w}, \max }$ are arbitrary. The influence of film cooling intensity is stronger than that of internal cooling, especially when turbine inlet temperature is higher. The relative influence of the thermal conductivity of TBC is even smaller than internal cooling. In conclusion, this comparison also suggests the importance of film cooling at higher thermal load.

In the end, it is important to see that these quantitive results are based on a specific vane and at certain cooling techniques, which may not be suitable to all the 1 st stage vanes. Nevertheless, similar sensitivity analysis could be carried out to other turbine vanes using the SIDO method introduced in this paper. It is inferred that the SIDO method would give valuable reference to the vane cooling design and $R \& D$ of future gas turbine.

\section{CONCLUSION}

A semi-inverse design optimization (SIDO) method for the film cooling arrangement of HPT vanes is introduced and verified in this paper. The SIDO method uses a 1D heat conduction model to calculate the constraint of the optimization, that the limitations of wall temperature is described by a minimal film cooling effectiveness. The optimization objective is to minimize the coolant amount. Together with CFD runs for various heat transfer parameters, a combinatorial optimization model can be built. The optimization model is then solved by an improved genetic algorithm (GA). The optimal film cooling arrangement and a minimal coolant amount could be found according to the thermal load of the vane and the cooling scheme adopted. A CHT CFD verification demonstrates that the cooling structure designed by the automated SIDO method is equivalent or even better than the manually designed.

The optimal coolant amount at various design conditions are studied utilizing the SIDO method. Regarding the optimal coolant amount from PS and SS, turbine inlet temperature and maximal metal temperature allowed are arbitrary. The relative influence of the thermal conductivity of TBC is more significant when its value is low. The quantitive results also suggests that developing film cooling technology should be more effective than developing internal cooling when the turbine inlet temperature gets higher.

\section{ACKNOWLEDGMENT}

The authors would like to acknowledge the financial supports from National Natural Science Foundation of China (No. 51506119) and China Postdoctoral Science Foundation.

\section{References}

[1] Lighthill, M., 1945, "A New Method of Two-Dimensional Aerodynamic Design,” Aeronautical Research Council R\&M 1111.

[2] Korn, D. G., 1978, "Numerical Design of Transonic Cascades," Journal of Computational Physics, Vol. 29, pp. 20-34.

[3] Léonard, O., Van den Braembussche, R. A., 1992, "Design Method for Subsonic and Transonic Cascade with Prescribed Mach Number Distribution," ASME J. Turbomach., Vol. 114, pp. 553-560.

[4] De Vito, L., Van den Braembussche, R. A., Deconinck, H., 2003, "A Novel Two Dimensional Viscous Inverse Design Method for Turbomachinery Blading" ASME J. Turbomach., Vol. 125, pp. 310-316. 
[5] Dulikravich, G. S., 1992, "Aerodynamic Shape Design and Optimization: Status and Trends," Journal of Aircraft, Vol. 29, pp. 1020-1026.

[6] Dulikravich, G. S., Martin, T. J., Dennis, B. H., 1999, "Multidisciplinary Inverse Problems", Proceedings of Inverse Problems in Engineering: Theory and Practice, Port Ludlow, WA, USA, June 13-18, 1999.

[7] Martin, T. J., 2001, "Computer-Automated Multi Disciplinary Analysis and Design Optimization of Internally Cooled Turbine Blades," Thesis for Ph. D. Degree of Pennsylvania State University.

[8] Talya, S. S., Chattopadhyay, A., Rajadas, N. J., 2002, "Multidisciplinary Design Optimization Procedure for Improved Design of a Cooled Gas Turbine Blade", Engineering Optimization, Vol. 34, pp. 175-194.

[9] Martin, T. J., Dulikravich, G. S., 2001, "Aero-Thermo- Elastic Concurrent Optimization of Internally Cooled Turbine Blades," In: A. Kassab, M. Aliabadi (Eds.), Coupled Field Problems, Series of Advances in Boundary Elements, WIT Press, Boston, MA, pp. 137-184.

[10] Dulikravich, G. S., Martin, T. J., Dennis, B. H., Foster, N., 1999, "Multidisciplinary Hybrid Constrained GA Optimization, Evolutionary Algorithms in Engineering and Computer Science," In: Miettinen, K., Makela, M. M., Neittaanmaki, P., Periaux, J. (Eds.), Recent Advances and Industrial Applications, Wiley \& Sons.

[11] Verstraete, T., Coletti, F., Bulle, J., Vanderwielen, T., and Arts, T., 2011, "Optimization of a U-Bend for Minimal Pressure Loss in Internal Cooling Channels - Part I: Numerical Method," Proceedings of ASME Turbo Expo 2011, No. GT2011-46541.

[12] Coletti, F., Verstraete, T., Vanderwielen, T., Bulle, J., and Arts, T., 2011, "Optimization of a U-Bend for Minimal Pressure Loss in Internal Cooling Channels - Part II: Experimental Validation," Proceedings of ASME Turbo Expo 2011, No. GT2011-46555.

[13] Lee, K. D. and Kim, K. Y., 2010, "Shape Optimization of a Fan-Shaped Hole to Enhance Film-Cooling Effectiveness,"
Int. J. Heat Mass Transf., Vol. 53, pp. 2996-3005.

[14] Lee, K. D. and Kim, K. Y., 2011, "Surrogate Based Optimization of a Laidback Fan-Shaped Hole for Film-Cooling," Int. J. Heat Fluid Flow, Vol. 32, pp. 226-238.

[15] Chi, Z., Li, X., Han, C., Ren, J., and Jiang, H., 2014 "Optimization of the Hole Exit Shaping of Film Holes without and with Compound Angles for Maximal Film Cooling Effectiveness", Proceedings of ASME Turbo Expo 2014, No. GT2014-25212.

[16] Chi, Z., Ren, J., and Jiang, H., 2014, "Coupled Aero- Thermodynamics Optimization for the Cooling System of a Turbine Vane", ASME J. Turbomach., Vol. 136, pp. 051008.

[17] Johnson, J. J., King, P. I., Clark, J. P., and Ooten, M. K., 2012, "Genetic Algorithm Optimization of an HPT Vane Pressure Side Film Cooling Array," Proceedings of ASME Turbo Expo 2012, No. GT2012-68049.

[18] Chi, Z., Wang, S., Ren, J., and Jiang, H., 2012, "Multi Dimensional Platform for Cooling Design of Air- Cooled Turbine Blades," Proceedings of ASME Turbo Expo 2012, No. GT2012-68675.

[19] Siegel, R. and Spuckler, M., 1998, "Analysis of Thermal Radiation Effects on Temperatures in Turbine Engine Thermal Barrier Coatings," Mater. Sci. Eng. A, Vol. 245, pp. 150-159.

[20] Bogard, D. G. and Thole, K. A., 2006, "Gas turbine film cooling," Journal of Propulsion and Power, Vol. 22, Issue 2, pp. 249-270.

[21] Goldberg, D. E., 1989, "Genetic Algorithms in Search, Optimization and Machine Learning," Addison Wesley Longman Inc.

[22] Beasley, J. E. and Chu, P. C., 1996, "A Genetic Algorithm for the Set Covering Problem," Eur. J. Opera. Res., Vol. 94, pp. 392-404.

[23] Li, X., Ren, J., and Jiang, H., 2013. "Algebraic Anisotropic Turbulence Modeling of Compound Angled Film Cooling Validated by PIV and PSP Measurements,", Proceedings of ASME Turbo Expo 2013, No. GT2013-94662. 